\title{
Enhancement of Mechanical Properties of Pure Aluminium through Contactless Melt Sonicating Treatment
}

\author{
Agnieszka Dybalska ${ }^{1, *(\mathbb{D}}$, Adrian Caden ${ }^{1}$, William D. Griffiths ${ }^{1}$, Zakareya Nashwan ${ }^{1}$, Valdis Bojarevics ${ }^{2}$, \\ Georgi Djambazov ${ }^{2}$, Catherine E. H. Tonry ${ }^{2}$ and Koulis A. Pericleous ${ }^{2} \mathbb{D}$ \\ 1 School of Metallurgy and Materials, University of Birmingham, Birmingham B15 2TT, UK; \\ J.A.Caden@bham.ac.uk (A.C.); W.D.Griffiths@bham.ac.uk (W.D.G.); ZSN584@student.bham.ac.uk (Z.N.) \\ 2 Centre for Numerical Modelling and Process Analysis, University of Greenwich, London SE10 9LS, UK; \\ v.bojarevics@gre.ac.uk (V.B.); g.djambazov@gre.ac.uk (G.D.); C.Tonry@gre.ac.uk (C.E.H.T.); \\ k.pericleous@gre.ac.uk (K.A.P.) \\ * Correspondence: dybalska.ag@gmail.com
}

\section{check for} updates

Citation: Dybalska, A.; Caden, A.; Griffiths, W.D.; Nashwan, Z.; Bojarevics, V.; Djambazov, G.; Tonry, C.E.H.; Pericleous, K.A. Enhancement of Mechanical Properties of Pure Aluminium through Contactless Melt Sonicating Treatment. Materials 2021, 14, 4479. https://doi.org/10.3390/ ma14164479

Academic Editors: Donatella Giuranno and Wojciech Polkowski

Received: 28 June 2021

Accepted: 3 August 2021

Published: 10 August 2021

Publisher's Note: MDPI stays neutral with regard to jurisdictional claims in published maps and institutional affiliations.

Copyright: (c) 2021 by the authors. Licensee MDPI, Basel, Switzerland. This article is an open access article distributed under the terms and conditions of the Creative Commons Attribution (CC BY) license (https:/ / creativecommons.org/licenses/by/ $4.0 /)$.

\begin{abstract}
A new contactless ultrasonic sonotrode method was previously designed to provide cavitation conditions inside liquid metal. The oscillation of entrapped gas bubbles followed by their final collapse causes extreme pressure changes leading to de-agglomeration and the dispersion of oxide films. The forced wetting of particle surfaces and degassing are other mechanisms that are considered to be involved. Previous publications showed a significant decrease in grain size using this technique. In this paper, the authors extend this research to strength measurements and demonstrate an improvement in cast quality. Degassing effects are also interpreted to illustrate the main mechanisms involved in alloy strengthening. The mean values and Weibull analysis are presented where appropriate to complete the data. The test results on cast Al demonstrated a maximum of $48 \%$ grain refinement, a $28 \%$ increase in elongation compared to $16 \%$ for untreated material and up to $17 \%$ increase in ultimate tensile strength (UTS). Under conditions promoting degassing, the hydrogen content was reduced by $0.1 \mathrm{~cm}^{3} / 100 \mathrm{~g}$.
\end{abstract}

Keywords: ultrasonic treatment; contactless sonotrode; strength; elongation; degassing; cavitation; Weibull modulus

\section{Introduction}

The metal casting industry and academic communities are extremely interested in improving melt quality. Microstructural refinement can be achieved, for example, by gating system optimization or melt inoculation [1-3]. Another promising route is the ultrasonic treatment (UST) of liquid metal. This method provides alloys with degassing, filtration and grain refinement [4-8]. Instead of the traditional immersed sonotrode, the contactless electromagnetic probe was recently developed to avoid melt contamination by probe damage due to corrosion in more reactive melts and to treat larger volumes of metal [9-11].

During processing, pressure vibrations induced in the melt by an external induction coil lead to acoustic resonance in the liquid alloy. This leads in turn to the oscillation of entrapped gas bubbles followed by their eventual collapse, the phenomenon of cavitation. Cavitation requires an ultrasonic pressure intensity larger than the cavitation threshold $[5,6]$, and its presence is desirable in the melt as it leads to beneficial changes in the finished product.

The first observed benefit is that of degassing $[5,6,12,13]$. Usually in molten metal, some dissolved gases are present, for example, we can expect the presence of hydrogen in aluminium due to its high solubility [14]. Gas bubbles are formed on nucleation sites (for example oxide particles) and grow by the diffusion of dissolved gas from the melt into the bubble. In a solidified casting, bubbles become pore defects reducing the strength of the metal. 
In the presence of ultrasound waves, bubbles oscillate in size, in response to the changing acoustic pressure in the liquid. The bubbles' behaviour in the sound field is governed by the Bjerknes forces [15]. Those forces move the bubbles up or down the pressure gradient created by the sound waves, or cause them to accumulate at pressure nodes [15]. As a result, the bubbles that have not collapsed can coalesce and, due to buoyancy, float to the surface where the hydrogen is released into the atmosphere.

The second benefit is that of structure refinement. In the right conditions the bubbles will not only oscillate but finally collapse. This event leads to extreme local pressure changes due to the shock waves and high-speed jets produced $[5,6,16]$. Such pressure changes are expected to be large enough to cause mechanical stress in intermetallic crystals or oxides, causing fragmentation by cracks due to brittle fracture [17]. After de-agglomeration, dispersion occurs. In addition to these local high-speed jets, the whole volume of metal is also stirred.

The source of stirring is the time-averaged Lorentz force induced in the melt by the electromagnetic field generated by the contactless sonotrode [10]. The flow will disperse the de-agglomerated particles, which can then serve as nucleation sites facilitating heterogeneous crystallization [7,18-21]. This process is commonly known as the "activation" of impurities where the combined effect of dispersion and forced wetting, due to pressure differences in the liquid [5-7]. Finally, emerging crystals can also be broken by the shock waves reducing the grain sizes [5-7,22]. Under sonication, the growth of dendrites will be restricted, assisting equiaxed growth. As we treat the metal prior to solidification in the experiments shown here, this effect is less significant.

The improvement of the metal microstructure caused by contactless ultrasonication has been systematically reported [10,11,23-26]. The Hall-Petch equation [27] predicts that, as the grain size decreases, the Yield Strength increases. The strength is reduced by the porosity [14]. As a consequence, the reduction of the grain size and gas content due to ultrasound treatment result in metal strengthening. Previously observed grain size reduction occurring in pure aluminium and alloys inoculated by a grain refiner (introduced in quantities below those commercially used) assist in heterogeneous cavitation [10,11,23-26].

To investigate the metal quality, the Yield Strength (YS) or Ultimate Tensile Strength (UTS) and percentage elongation (L\%) are commonly found by testing metal samples. Statistically, the fracture is described by the Weibull distribution based on the weakest link theory $[28,29]$. The cumulative probability function of the two-parameter Weibull distribution is, therefore, expressed as follows (Equation (1)):

$$
\mathrm{P}=1-\exp \left[-\left(\sigma \sigma_{0}^{-1}\right)^{\mathrm{m}}\right]
$$

where $P$ is the probability of failure at a given property (stress, strain, fatigue life, etc.), $\sigma$, or lower. The parameter $\sigma_{0}$ is a distribution scale parameter, and $\mathrm{m}$ is the shape parameter. The shape parameter is also known as the Weibull modulus, a parameter that reflects how much the data are scattered, with a higher Weibull modulus meaning a lower probability of fracture under stress.

This approach has been adapted for metallurgy and has been widely used [29-31]. The Weibull modulus, established from the tensile strength for gravity-filled castings, is generally thought to range between 10 and 30. For aerospace castings, it is expected to be between 50 and 100 [32]. For example, it is about 73.8 for a ductile steel 1018, 91.4 for an aluminium alloy AL 7075-T651 and can be as high as 124.0 for Al 6061-T651 alloy [33].

This paper shows recent tensile test results (UTS and elongation) of ultrasonicated metal, demonstrating improvements in the cast metal quality. Degassing effects and microstructure refinement are interpreted to analyse the main mechanisms involved in alloy strengthening. 


\section{Materials and Methods}

Casting experiments were conducted in a cylindrical clay-graphite crucible with an external diameter of $170 \mathrm{~mm}$, an internal diameter of $135 \mathrm{~mm}$ and a height of $320 \mathrm{~mm}$. For each experiment, the crucible was filled with about $8.5 \mathrm{~kg}$ of metal-a commercial purity aluminium (CP-Al) with the addition of $0.15 \mathrm{wt} . \% \mathrm{Al}-5 \mathrm{Ti}-1 \mathrm{~B}$ grain refiner to increase the potential number of nucleation sites for cavitation. The amount of grain refiner is small enough to make changes in the microstructure easily observable. The prototype "top-coil" (a "first generation" contactless sonotrode) [9-11] was used for the sonication of the liquid metal. During processing, the ambient ultrasonic noise emitted around the crucible was recorded by an Ultramic ${ }^{\circledR}$ 200K (Dodotronic, Castel Gandolfo, Italy) digital ultrasonic microphone.

The recorded sound was observed in the form of an FFT (Fast Fourier Transform) sound spectrum extracted in real-time during experiments using MATLAB ${ }^{\circledR}$ Online (MathWorks, Natick, MA, USA) software. The broadband noise emitted by collapsing bubbles $[23,34]$ acted as an indicator of the presence of cavitation. Broadband noise was seen as light-coloured vertical lines on spectrograms recorded under varying conditions. The lines were normal to the continuous horizontal lines denoting the top-coil frequency signal, observed at around $20 \mathrm{kHz}$, and the induction furnace signal, observed at around $5 \mathrm{kHz}$. Cavitation was seen to be intermittent, and the number and density of vertical lines was considered to be a good indication of cavitation activity [23,35].

Where broadband noise was observed, the process conditions (coil frequency and melt temperature) responsible for the noise were maintained and at least 1-2 min of processing was recorded and presented on the spectrograms. In some cases, the local conditions in the setup resulted in near-resonant conditions in the crucible, where bubbles could oscillate continuously at their own resonant frequency but did not implode. By 'local conditions' we mean the parameters such as the melt volume or the off-axis position of the crucible relative to the top-coil head and others. When that happened, only degassing was observed.

The results of that degassing were compared with processing followed by grain size change. In each case, after $4-5$ min of processing, samples were taken using the KBI ring test [36]. For this test, the liquid metal was poured into a steel ring with an outside diameter of $75 \mathrm{~mm}$, inside diameter $50 \mathrm{~mm}$ and height of $25 \mathrm{~mm}$ placed on an insulating silica brick. Typically, the mass of aluminium samples is $70-100 \mathrm{~g}$. To characterize the grain size, the base of the cylindrical samples were removed to about $3 \mathrm{~mm}$ above the base and ground, polished and etched with either Poultons' or Kellers' solution.

The average grain size was then determined by the mean linear intercept method after taking photographs using a Zeiss Axioskop 2 (Zeiss, Oberkochen, Germany) microscope equipped with an AxioCam HRc camera (Zeiss, Oberkochen, Germany). To show the samples with a larger magnification, the standard microstructure photographs were taken by a Fuji camera (Fujifilm, Minato CITY, Tokyo, Japan) with optical zoom.

Following the KBI ring test, a second sample was poured into a Severn Science Gas Analyser (MechaTech Systems Ltd., Thornbury, Bristol, UK) to determine the hydrogen content. The remainder of the processed metal was poured into a sand mould (see Figure 1) in order to obtain tensile test-bars, which were later machined to the size required for the tensile strength tests. 


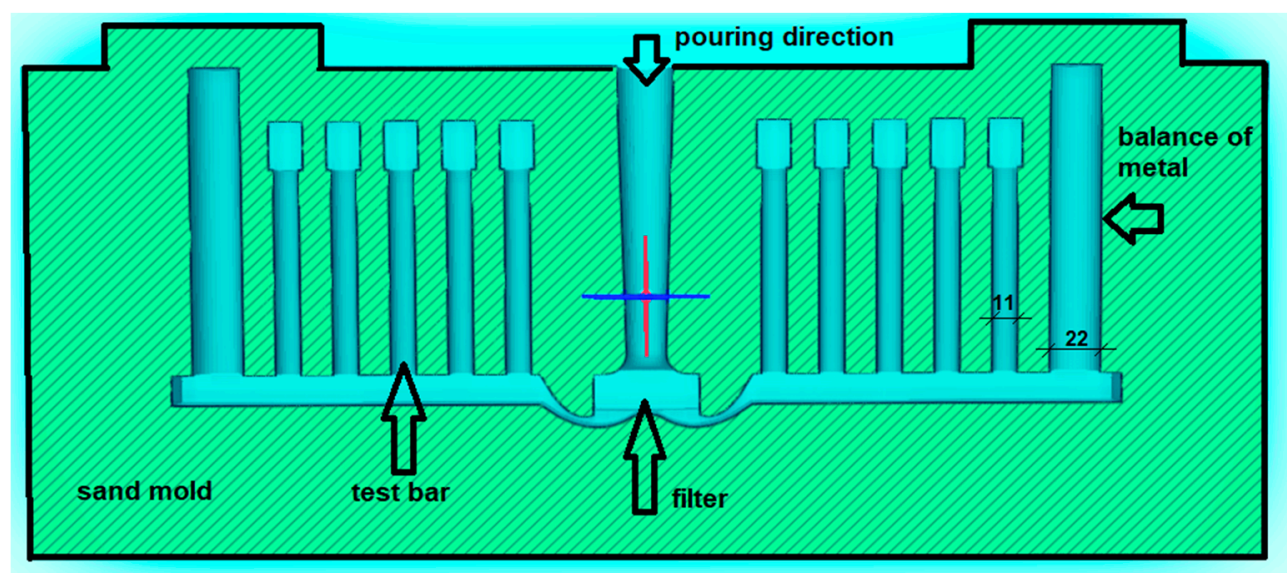

Figure 1. The draft of the sand mould used for casting of 10 test-bars for tensile strength tests. The two crucial diameters are given in $\mathrm{mm}$, and the sketch scale is 1:1. Liquid metal is poured into the mould from the top opening; it passes the filter and feeds the 10 test-bars cavities (diameter $11 \mathrm{~mm}$ ). The higher cavities on both ends (diameter $22 \mathrm{~mm}$ ) balance the pressure to feed the mould correctly.

In each experiment, one mould was cast, and 10 tensile specimens were produced. Producing more than 10 test-bars in one experiment is difficult due to the low initial temperature used. It is easier to release dissolved hydrogen from the melt at lower temperatures; hence, the cavitation intensity decreased with the temperature increase and almost disappeared at $720^{\circ} \mathrm{C}$. Thus, the processing happened at $710^{\circ} \mathrm{C}$. That low temperature shortened the time frame for casting into the mould. Due to fluidity loss with time, filling two moulds was difficult.

The cast metal was filtered using a 20 ppi filter to avoid the presence of excessive oxide films. The process was repeated without ultrasound processing, to obtain reference test-bars. In that case, instead of the ultrasonic processing, the liquid metal was left inside the induction furnace at the same temperature as before for the time usually required for the contactless sonotrode treatment. Both the reference and processed samples were tested with an applied strain rate of $1 \mathrm{~mm} / \mathrm{min}$ by the Zwick/Roell Z030 Universal Mechanical Tester (Zwick Roell Group, Ulm, Germany), equipped with a micro-extensometer.

The data obtained were analysed with the help of scripts in MATLAB and R-Studio software. To establish the Weibull modulus by the linear regression method [37-40], unbiased estimators were used following the approach described in [37] depending on the sample size (n-number of measurements). The general form of the estimator used in that procedure was (Equation (2)):

$$
P=(i-a)(n+b)^{-1},
$$

where $i$ is the rank of the data point in the sample in ascending order, $n$ represents the sample size, and $\mathrm{a}$ and $\mathrm{b}$ are numbers specific for the sample size found by the computer simulation [37].

For a sample size $\mathrm{n}=20$, that estimator is in the form (Equation (3)):

$$
P=(i-0.417)(n+0.030)^{-1},
$$

while for $\mathrm{n}=10$, it is (Equation (4)):

$$
P=(i-0.348)(n+0.190)^{-1} .
$$

Where other estimators were used, the estimator form is given in the text. The coefficient of determination $\left(R^{2}\right)$ for each regression line is also presented.

The error was estimated by the simulation in MATLAB. The Weibull modulus $\mathrm{M}^{\prime}$ was found by linear regression after sampling 10 or 20 unique and random values from the distribution with the chosen shape parameter $\mathrm{m}=\mathrm{M}$. This procedure was repeated 
50,000 times, and the mean value and the standard deviation of the mean were extracted. The ratio of $\mathrm{M}^{\prime}$ (found from 10 or 20 values) and Weibull modulus $\mathrm{M}$ set as a "true" value in the program, was treated as the bias of the method (compare: [38]).

\section{Results}

\subsection{Grain Refinement after Sonication}

Experiments denoted 1 and 2 are the principle results in this paper. The effects of the first treatment (Experiment 1) are presented below in Figure 2. The grain size of a processed metal $(b, d)$ is compared with the initial grain size observed in the untreated metal $(a, c)$. As can be seen in the image without microscopic magnification $(c, d)$ the grain size decreased strongly. From the photographs taken in the microscope, the decrease was of about $48 \%$ from the initial size. The exact grain sizes are given in Figure 2.
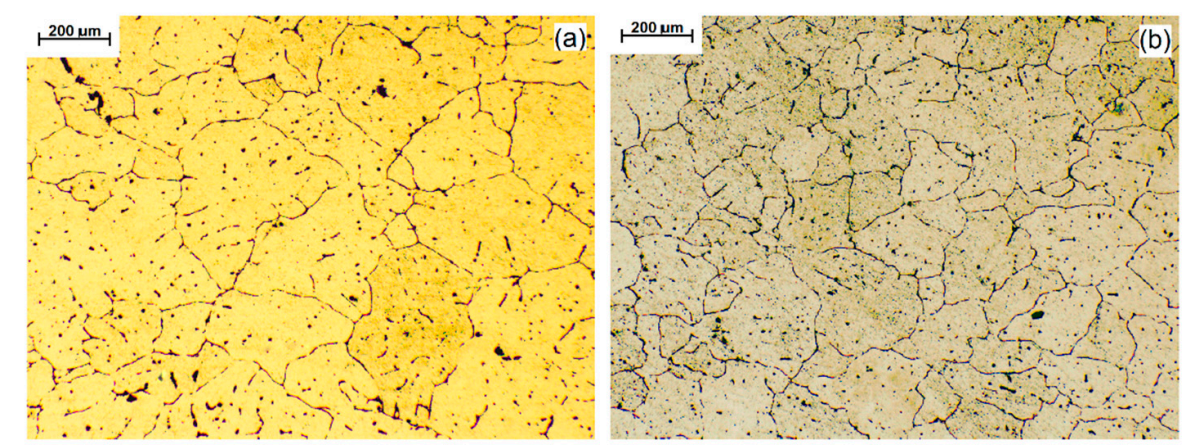

(c)

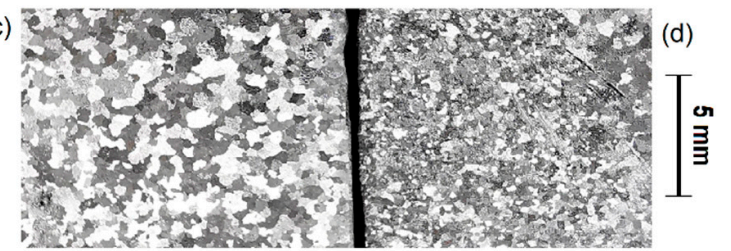

Figure 2. Experiment 1: (a) The grain size of untreated metal $(208 \pm 38 \mu \mathrm{m})$ and (b) after treatment $(108 \pm 19 \mu \mathrm{m})$ decreased by $48 \%$, which is clearly indicated by a macro-scale photograph of a sample taken (c) before and (d) after ultrasonication.

In the next experiment (denoted experiment 2), another set of test-bars was cast, and the grain sizes of the metal before and after treatment are presented in Figure 3. The initial grain size was similar to the previously prepared reference set (Figure 2c). In this case, the grain size decreased by about $28 \%$ from that value.
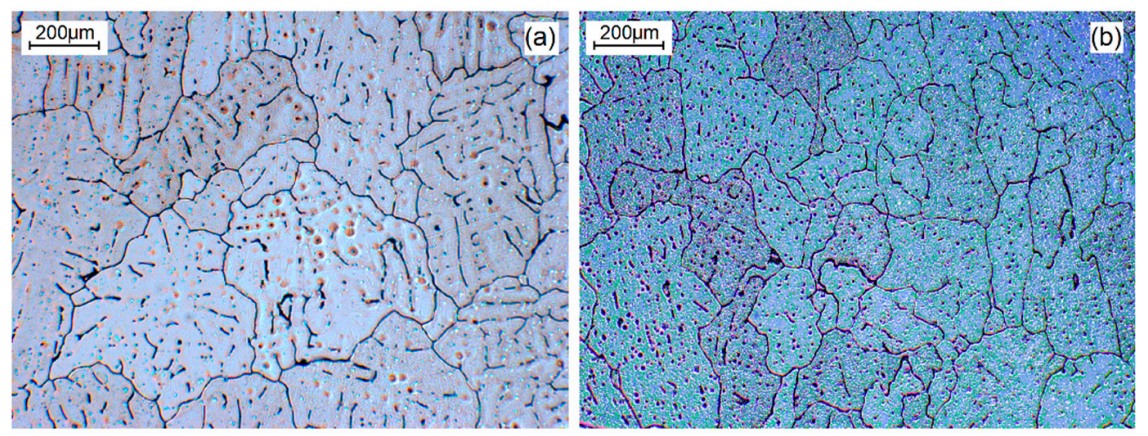

Figure 3. Experiment 2: (a) The grain size of untreated metal $(204 \pm 13 \mu \mathrm{m})$ and (b) after treatment $(147 \pm 4 \mu \mathrm{m})$ decreased by about $28 \%$.

The decrease in grain size is the effect of metal ultrasonication, which appears to be less effective in this case. The contactless sonotrode frequency was set in near-resonance conditions that were unique for each experiment. The spectrograms of the sound recorded 
near the crucible indicated the extent of cavitation during both experiments and are shown in Figure 4.

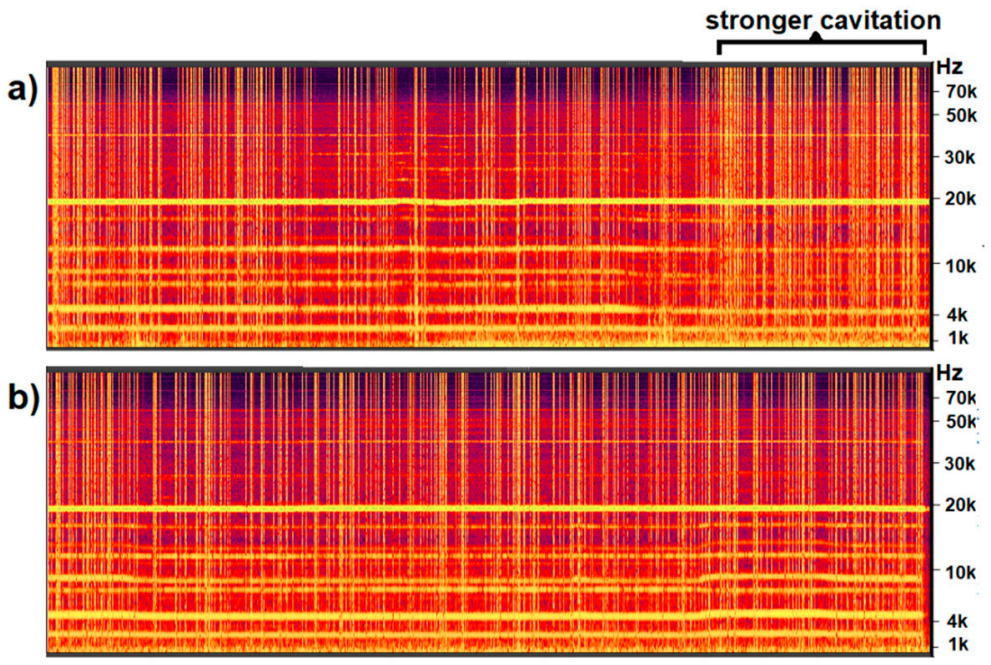

Figure 4. Spectrograms extracted from the recorded sound: (a) experiment 1, ultrasonication with frequency $18.86 \mathrm{kHz}$, and (b) experiment 2, ultrasonication with frequency $18.42 \mathrm{kHz}$. The time of recording in both cases was about $5 \mathrm{~min}$ long.

The vertical light lines, perpendicular to the sonotrode signal seen as a horizontal line at $20 \mathrm{kHz}$, can be treated as an indication of cavitating bubbles [23,34]. In both cases, almost all the treatment time was recorded. In the first experiment, we see that the cavitation intensity appeared to be higher at the end of the process. This could be an explanation as to why the grain size in this experiment decreased by $48 \%$, while in the second case, the decrease was only $28 \%$. It is not unusual for the effects to be different in each experiment.

The cavitation intensity depends on the local conditions, including the liquid volume, temperature, crucible position, crucible wall material etc., as this is the frequency that causes the resonance [34]. For industrial use, keeping those conditions constant would be possible in a specially designated set-up using a feedback mechanism; however, in this experimental set-up, it is difficult. Each experiment is, therefore, unique, and the near-resonant frequency is found in real-time by the operator observing the FFT of the recorded noise. Thus, the cavitation intensity differs in individual treatments, and the observed grain size reflects that intensity.

\subsection{Gas Content Decrease Due to Sonication}

In both the experiments presented above, the degassing potency of the contactless sonotrode was determined. The gas content before and after processing is given in Table 1 and compared with results of similar experiments in which only the degassing level was determined. The two experiments described before, in which test-bars were produced (Figures 2-4), are labelled as Ex1 (experiment 1) and Ex2 (experiment 2) in this paper.

Table 1. Degassing achieved by contactless ultrasound treatment.

\begin{tabular}{|c|c|c|c|c|c|c|}
\hline & $\begin{array}{l}\text { Frequency } \\
\quad(\mathbf{k H z})\end{array}$ & $\begin{array}{c}\text { Temperature } \\
\left({ }^{\circ} \mathrm{C}\right)\end{array}$ & $\begin{array}{l}\text { Gas Content before } \\
\text { Treatment }\left(\mathrm{cm}^{3} / 100 \mathrm{~g}\right)\end{array}$ & $\begin{array}{c}\text { Gas Content after } \\
\text { Treatment }\left(\mathrm{cm}^{3} / 100 \mathrm{~g}\right)\end{array}$ & $\begin{array}{c}\text { Gas Content Decrease } \\
\left(\mathrm{cm}^{3} / 100 \mathrm{~g}\right)\end{array}$ & $\begin{array}{c}\text { Gas Content Decrease } \\
(\%)\end{array}$ \\
\hline Ex1 & 18.86 & 710 & 0.17 & 0.11 & 0.06 & $35 \%$ \\
\hline Ex2 & 18.42 & 710 & 0.16 & 0.12 & 0.04 & $35 \%$ \\
\hline Ex3 & 18.61 & 706 & 0.17 & 0.11 & 0.06 & $35 \%$ \\
\hline Ex4 & 18.32 & 700 & 0.15 & 0.04 & 0.11 & $73 \%$ \\
\hline $\operatorname{Ex} 5\left(^{*}\right)$ & 18.42 & 709 & 0.20 & 0.14 & 0.06 & $30 \%$ \\
\hline
\end{tabular}

$\left.{ }^{*}\right)$ degassing only—no grain refinement produced. 
Both experiments (Ex1 and Ex2) were accompanied by a decrease in the gas content of about $0.05 \mathrm{~cm}^{3} / 100 \mathrm{~g}$. As can be seen in the example of experiment Ex4, the degassing can be much stronger. The maximum change (Ex4) of the gas content was about two-times greater than in experiments Ex 1-3. Slightly less of a degassing effect in Ex2 than in Ex1 can be associated with the smaller cavitation intensity, manifested by a smaller grain refinement effect (compare with Figures 2-4).

Previous examples of reported gas content decreased due to traditional ultrasound processing from 0.35 to $0.17 \mathrm{~cm}^{3} / 100 \mathrm{~g}$ [13] - a reduction of $50 \%$. In experiment 4 , the gas content decreased by 3.75 times. Unfortunately, the alloy used in [13] and the processing conditions were different; however, the efficiency of the contactless sonotrode in degassing seems to be at least comparable.

To summarise, the results presented show that contactless sonication provides: (I) grain refinement, and (II) degassing. Then, the open question is, how does the ultrasound treatment improve the strength of processed metals? As mentioned in the introduction, both effects - the grain size decrease and the gas content reduction should improve the cast metal quality. To determine how the described changes influenced the strength of the alloy in Ex1 and Ex2, in which elongation and UTS were measured, in Table 2, the mean values of elongation before and after treatment are given.

Table 2. Mean elongation before $(\mathrm{L})$ and after $\left(\mathrm{L}^{\prime}\right)$ treatment.

\begin{tabular}{|c|c|c|c|c|}
\hline & L (\%) Reference & $L^{\prime}(\%)$ after Treatment & $\mathbf{L}^{\prime} / \mathbf{L}$ & $\mathrm{L}^{\prime} / \mathrm{L}\left({ }^{*} 100 \%\right)$ \\
\hline Ex1 & \multirow{3}{*}{$15.9 \pm 3.0$} & $27.5 \pm 6.5$ & 1.73 & $173 \%$ \\
\hline Ex2 & & $24.2 \pm 4.2$ & 1.52 & $152 \%$ \\
\hline $\operatorname{Ex} 5\left(^{*}\right)$ & & $15.5 \pm 6.5$ & 0.98 & $98 \%$ \\
\hline
\end{tabular}

$\left({ }^{*}\right)$ degassing only, no grain refinement.

\subsection{Elongation after Sonication}

The mean elongation after treatment was 52-73\% greater than that observed for the same alloy without sonication. These results are consistent with previous findings-in experiment 1, we observed a greater grain size decrease and slightly more degassing than in experiment 2 . This was followed by better metal quality. In comparison with the degassed only samples (Ex5), an assumption can be made that the degassing at this level played a negligible effect, and thus the main mechanism in the improvement is associated with the grain size decrease. Aluminium belongs to the class of ductile materials, and an improved elongation is important for future applications of the metal.

As mentioned before, each unique experiment produced a casting of 10 test-bars. For the reference set, the temperature history of the melt was repeated, and we were able to produce equivalent tensile specimens. Thus, the reference values of both (UTS and elongation) tests were established from 20 results. As expected, the observed error was smaller in that case than for experiments Ex1 and Ex2, where only 10 specimens were tested, as can be seen in Figure 5.

Even taking into account the error shown in Figure 5, both measured values for metal samples cast after ultrasonic treatment were much higher than those observed for the reference samples. The two left arrows in Figure 5 show the minimal observed differences. The next two arrows represent differences between the mean values. The mean elongation increased maximally by about $11.5 \%$, which makes it 1.72 -times greater than that observed for the reference specimens. 


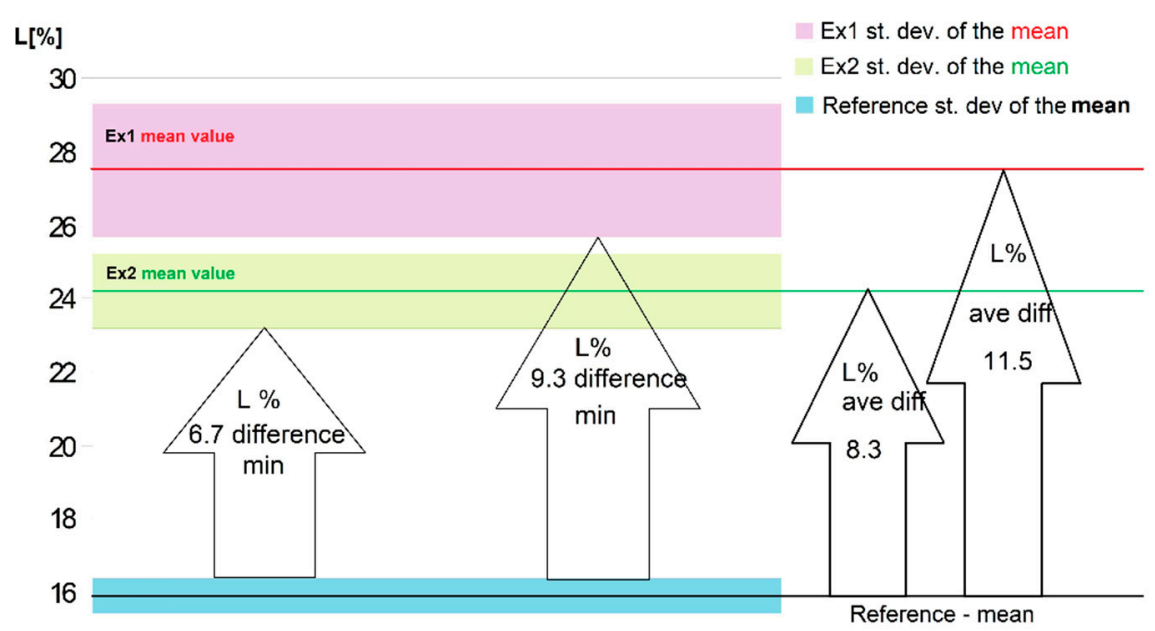

Figure 5. Measurements of elongation - the mean values and the error found in each experiment. The arrows show the minimum differences between elongation with and without treatment (difference $\mathrm{min}$ ) or the difference between the mean values (average difference).

\subsection{Ultimate Tensile Strength (UTS) after Sonication}

In Table 3, the mean UTS before and after treatment is presented.

Table 3. The mean UTS before (UTS) and after $\left(\mathrm{UTS}^{\prime}\right)$ treatment.

\begin{tabular}{|c|c|c|c|}
\hline & UTS (MPa) Reference & UTS $^{\prime}$ (MPa) after Treatment & UTS'/UTS (*100\%) \\
\hline Ex1 & & $79 \pm 1.3$ & $117 \%$ \\
\hline Ex2 & $67.4 \pm 2.6$ & $72 \pm 2.6$ & $107 \%$ \\
\hline $\operatorname{Ex} 5\left(^{*}\right)$ & & $65.6 \pm 4.5$ & $98 \%$ \\
\hline
\end{tabular}

The mean UTS before and after treatment was greater than the reference set increasing from about $7 \%$ to $17 \%$. The metal cast in the experiment resisted, without permanent damage, a pressure of about $12 \mathrm{MPa}$ greater than the reference samples. To help understand these results, the Weibull distribution was fitted into the UTS data. Weibull plots of the ultimate tensile strength (UTS) data of the castings are presented in Figure 6.

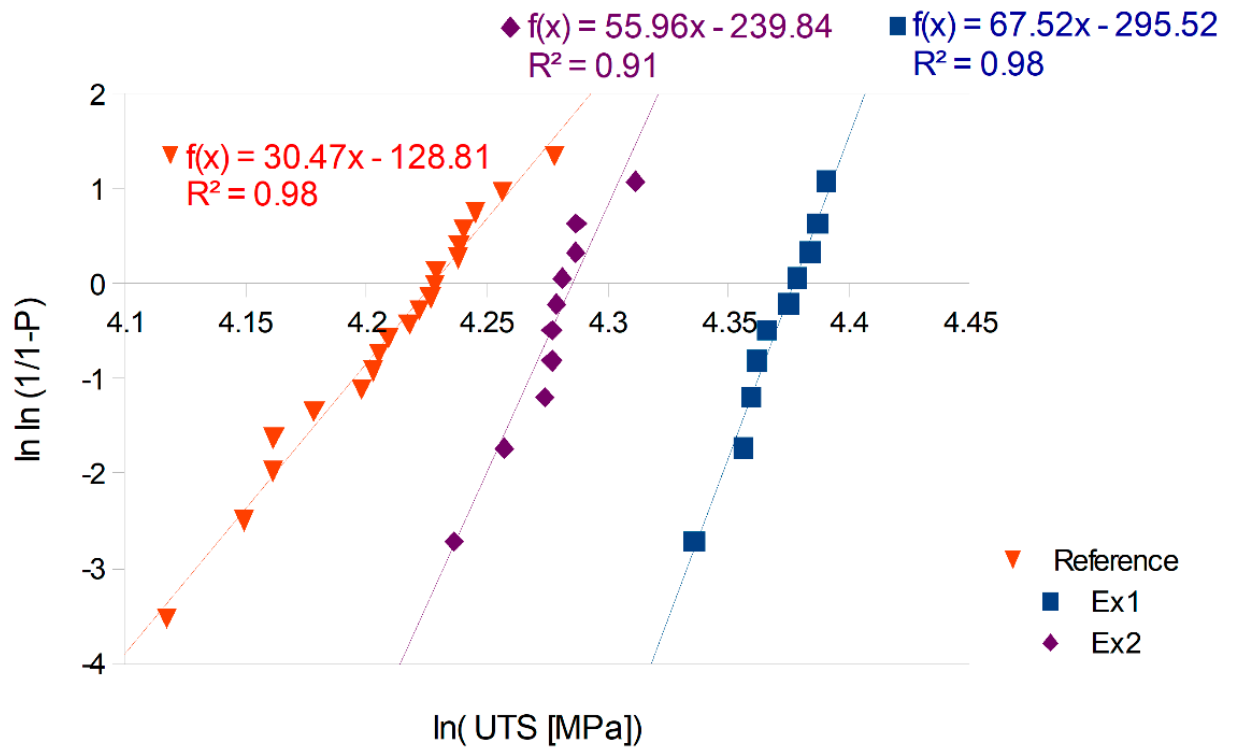

Figure 6. The Weibull modulus established by the linear regression. 
From the regression line equations, the Weibull modulus $(\mathrm{m})$ of the reference set equalled $\mathrm{m}_{0}=30.5$. After treatment, this modulus increased to $\mathrm{m}_{1}=67.5$ in Ex1 and $\mathrm{m}_{2}$ $=56.0$ in Ex2. The data were fitted to Weibull distributions of $\mathrm{m}_{1}$ and $\mathrm{m}_{2}$ (and calculated scale parameters), and the curves of the Weibull probability plots are presented in Figure 7.

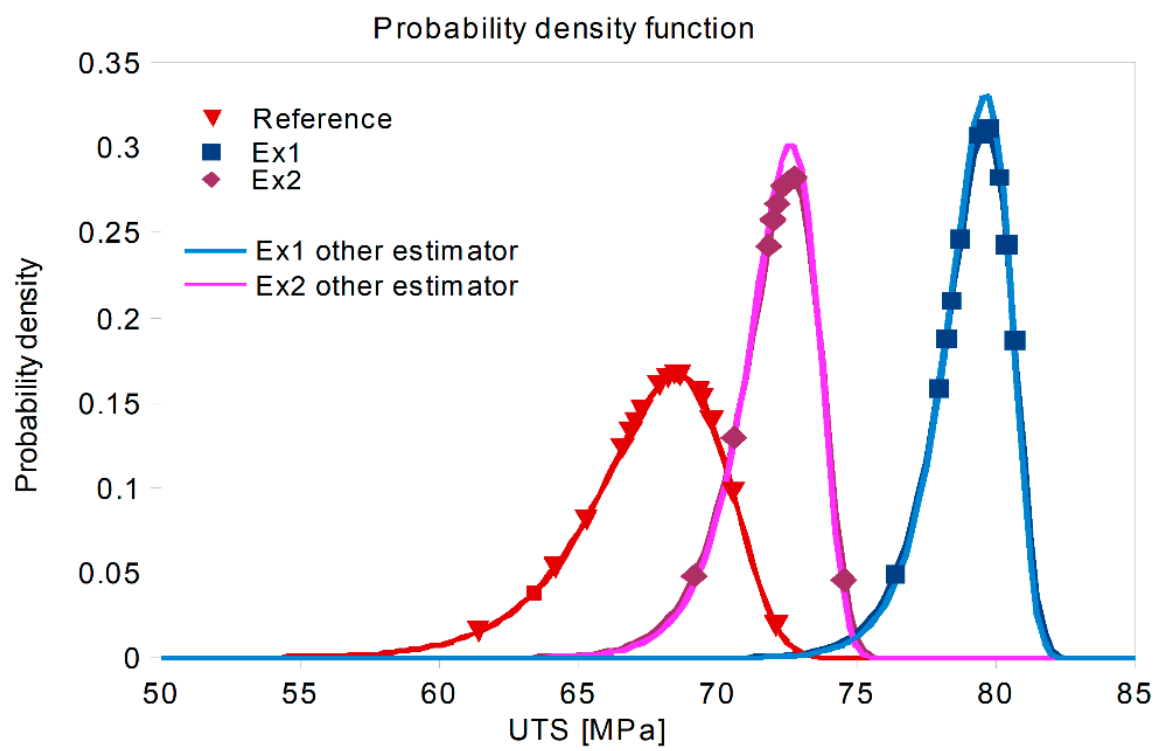

Figure 7. The probability density function (Weibull curve) of the reference data versus the results of both ultrasound treatments based on UTS measurements. The data points are overlayed on the calculated distribution indicated in Figure 6. Two lines labelled as "other estimator" show the other possible distributions, calculated with another estimator, as will be discussed further (method 3 in Table 4).

The shape of the distribution curve attributed to data from Experiment 1 shows that the expected scatter of the results was much smaller than that for the reference set. This is indicated by the narrower Weibull curve governed by the shape parameter $(\mathrm{m}$, also known as the Weibull modulus). The results of Experiment 2 are better than those observed without treatment, and the Weibull curve is also "narrow". Changing the estimators does not change the Weibull distribution significantly (see Section 4.3).

\subsection{The Stress-Strain Curves}

Figures 8 and 9 present the stress-strain curves for all specimens, including both reference and treated (Ex1 and Ex2) metal.

In Figure 8, the failure region for the reference set was observed at much lower values of strain, and the maximum stress was higher than for untreated metal. Toughness, the ability of a material to absorb energy and plastically deform without fracturing, is defined by the area under the stress-strain curve [41]. The area under any of the experimental lines was larger than under the reference lines. The toughness of the material after ultrasound treatment in Ex1 was much higher than for the non-processed samples, which is a good prediction for future engineering applications. 


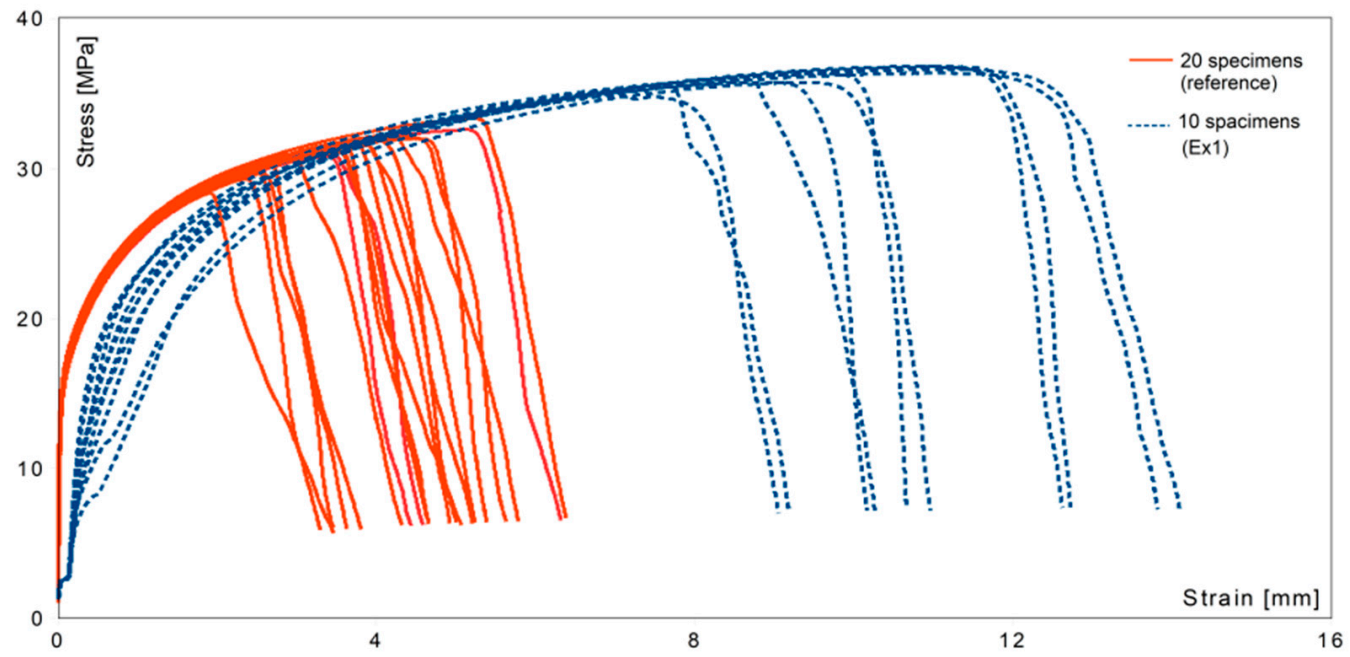

Figure 8. The stress versus the nominal strain curves for the specimens from the reference set and experimental (Ex1) set.

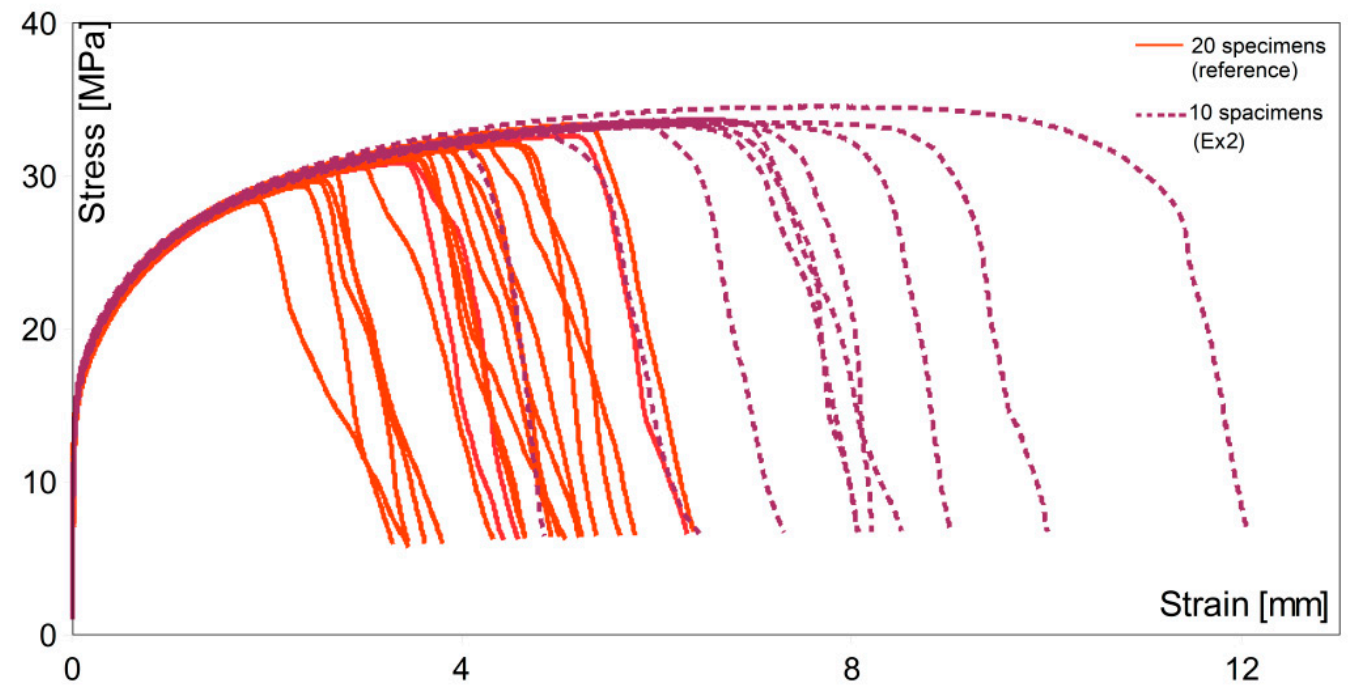

Figure 9. The stress versus the nominal strain curves for the specimens from the reference set and experimental (Ex2) set.

In the case of Ex2, the failure in most cases occurred much later than for the reference test bars. Two specimens broke out earlier. This can be caused by other effects, such as porosity or entrained oxide films. The overall effects of ultrasonic processing were positive and prove the efficacy of the contactless technique. The toughness of the material was also significantly improved. For most cases, the area under the curves was much larger than that recorded for the untreated metal. The variability between both experiments can be attributed to the slightly different processing conditions, which were manually controlled. It is necessary to develop a feedback mechanism continuously adjusting the coil frequency for resonance and an accurate pressure monitoring system to control conditions more precisely in an industrial situation. 


\section{Discussion}

\subsection{Dataset Validity}

Before comparing the results, Student's t-test was performed to decide if separately cast test-bars could be treated as coming from the same distribution. The first check confirmed that all samples produced as reference test-bars (obtained from two separate castings with repeated conditions) belonged to the same Weibull distribution and could be presented as one dataset (red triangles in Figure 6). The same test made for both experiments excluded the possibility that the data from Ex1 and Ex2 belonged to the same Weibull distribution. The results of that test (for Ex1 and Ex2) are shown in Figure 10.

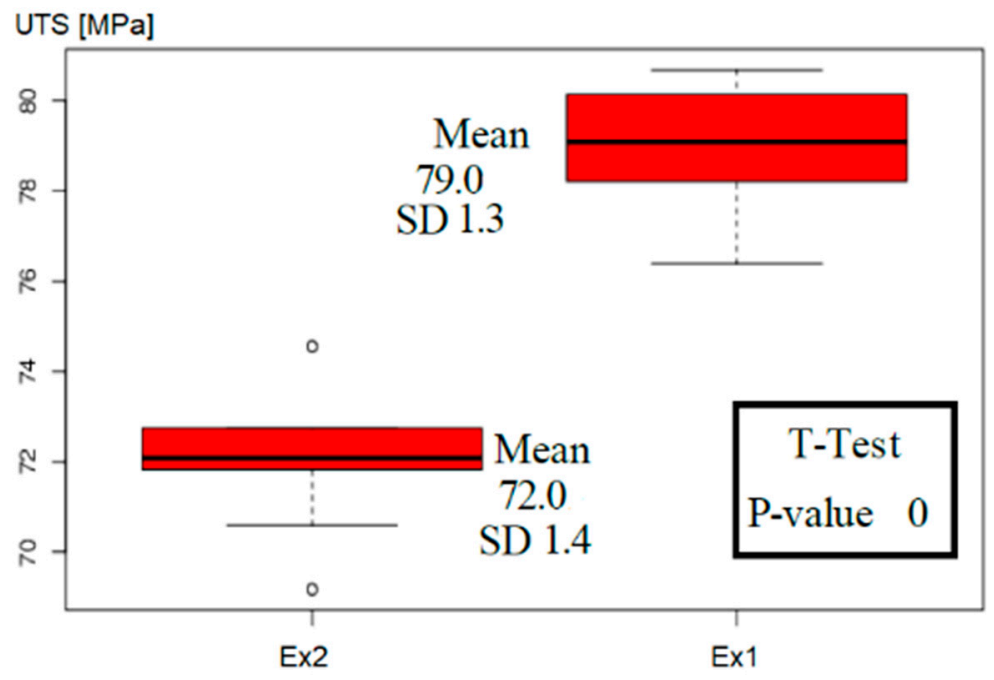

Figure 10. The results of two-sided t-tests of UTS measurements showing that Ex1 and Ex1 do not follow the same distribution. The test was done with $95 \%$ confidence.

The minimum p-value to accept the hypothesis that both experiments came from the same distribution was $p=0.05(5 \%)$; therefore, for our data, the test rejected this hypothesis. The results of the $t$-test confirmed that the results of each experiment must be presented separately (Figure 6). At this moment, we have to rely only on 10 measurements of the strength produced in each experiment. The error bound up with that procedure will be further discussed.

\subsection{Regression Validity}

One method allowing us to check the regression method validity by observing the $R^{2}$ value. There exists a minimum value of $R^{2}$ to accept the fit of the data to the Weibull distribution as calculated by the linear regression method [37]. When the sample size is equal to 20 , the minimum $R^{2}$ value is 0.894 , and the $R^{2}$ value must be over 0.855 for $n=10$. In Figure 6, the value of $R^{2}$ is presented, and the fit of lines found by regression were sufficient to accept all the presented data. For the elongation data, the fit was not sufficient to present the Weibull modulus found by regression.

\subsection{Validity of Comparison between Distributions}

Even considering the $\mathrm{R}^{2}$ test, the smaller sample size in the Weibull analysis resulted in an increased error [39]. To check if the results of the experiments (blue squares and purple diamonds in Figures 6 and 7) can be compared with the reference data (red triangles in Figures 6 and 7), we need to refer to the confidence intervals published earlier [34].

A comparison between two distributions (with known $\mathrm{m}$ and $\mathrm{m}^{\prime}$ ) of sizes $\mathrm{N}=20$ and $\mathrm{N}^{\prime}=10$ is possible with $95 \%$ confidence if [40]

$$
1.889<\mathrm{m}^{\prime} / \mathrm{m}<2.434
$$


For experiment 1 , the $\mathrm{m}^{\prime} / \mathrm{m}=\mathrm{m}_{1} / \mathrm{m}_{0}=2.216$. As this value is inside the confidence interval given above, there is $95 \%$ confidence in comparing the Weibull moduli of both of these distributions. For experiment 2, the $\mathrm{m}^{\prime} / \mathrm{m}=\mathrm{m}_{2} / \mathrm{m}_{0}=1.837$, and thus we can compare it with the reference results with $90 \%$ confidence (where the confidence interval starts for $1.695<\mathrm{m}^{\prime} / \mathrm{m}$ as given at [40]). Thus, even considering the errors, we can confirm the quality improvement for both treatments with over $90 \%$ confidence.

\subsection{Validation of Used Estimators}

Fitting the correct distribution when the sample size is small should be done with the correct method. Several proposed estimators $[38,40,42,43]$ and weighted linear regression $[44,45]$ have been validated for Ex1 and Ex2. The results of the Anderson-Darling goodness-of-fit test are presented in Table 4.

Table 4. The Anderson-Darling (AD) goodness of fit test for $\mathrm{m}$ calculated by unweighted linear regression (LR) or weighted linear regression (WLR) with different estimators. Already presented values are marked by bold font.

\begin{tabular}{cccccccc}
\hline No & Method & Used Estimator & \multicolumn{2}{c}{$\begin{array}{c}\text { Estimated m from } \\
\text { UTS Data }\end{array}$} & \multicolumn{2}{c}{$\begin{array}{c}\text { AD Test Result } \\
(\boldsymbol{p} \text {-Value })\end{array}$} & $\begin{array}{c}\text { Approach } \\
\text { Ref. }\end{array}$ \\
\hline & & & Ex1 & Ex 2 & Ex1 & Ex 2 & \\
\hline 1 & LR & $\mathrm{P}=(\mathrm{i}-0.5) / \mathrm{n}$ & 71.7 & 59.6 & 0.99 & 0.67 & {$[42]$} \\
\hline 2 & LR & $\mathrm{P}=(\mathrm{i}-0.348) /(\mathrm{n}+0.19)$ & $\mathbf{6 7 . 5}$ & $\mathbf{5 6 . 0}$ & 0.99 & 0.64 & {$[38]$} \\
\hline 3 & LR & $\mathrm{P}=(\mathrm{i}-0.44) /(\mathrm{n}+0.12)$ & 69.7 & 57.8 & 0.91 & 0.67 & {$[43]$} \\
\hline 4 & WLR & $\mathrm{P}=(\mathrm{i}-0.5) / \mathrm{n}$ & 59.6 & 56.3 & $\leq 0.05$ & 0.66 & {$[44,45]$} \\
\hline
\end{tabular}

The Anderson-Darling test rejects the dataset if the value $p \leq 0.05$. It simply means that, with $95 \%$ confidence, the data do not follow the chosen distribution. Both tested datasets show a good fit, with the $p$-value being on the extraordinary level of 0.99 for Ex1 validating previous analysis.

From Table 4, we can also conclude that the alteration of the estimators is not necessary, and the Anderson-Darling test did not show significant differences between all the tested methods.

\subsection{Expected Error}

To make further analysis easier, we rounded the m-values. For experiment 1 (see Table 4 ), the Weibull modulus was close to $\mathrm{m}_{1}=68$, and, for experiment $2, \mathrm{~m}_{2}=56$. The mean values of the elongation and UTS after treatment (Tables 2 and 3) prove that-even accounting for the maximum error-both experiments improved the quality of the processed metal.

One can query the exact expected error in the established value of the Weibull modulus. The goodness of fit results can indicate that the chosen distribution was fitted correctly, even if based on a small number of measurements. To be more precise in the error estimation, we considered the estimated value for Ex1. By the computer simulation, the standard deviation and confidence intervals were calculated and shown in published research $[38,40,45]$. The error found was about $33 \%$ when only 10 test-bars were used $[38,45]$. For confirmation of that value, the results of computer simulation with 50,000 cycles were used to estimate the bias and the error (the standard deviation of the mean Weibull modulus calculated by different methods). The results are presented in Table 5 . 
Table 5. The bias and the error comparison for methods (as in Table 4) used to estimate the Weibull modulus.

\begin{tabular}{|c|c|c|c|c|c|c|}
\hline & Method & $\mathbf{n}$ & $\mathbf{M}$ & $\mathbf{M}^{\prime}$ & Bias $\left(\mathbf{M}^{\prime} / \mathbf{M}\right)$ & Standard Deviation $\left(\mathbf{M}^{\prime}\right)$ \\
\hline \multirow{3}{*}{ Ex1 } & 1 & \multirow{3}{*}{10} & \multirow{3}{*}{68} & 71.94 & 1.05 & $32.5 \%$ \\
\hline & 2 & & & 68.57 & 1.01 & $32.2 \%$ \\
\hline & 3 & & & 70.71 & 1.03 & $32.4 \%$ \\
\hline \multirow{3}{*}{$\mathrm{Ex} 2$} & 1 & \multirow{3}{*}{10} & \multirow{3}{*}{56} & 59.49 & 1.06 & $32.3 \%$ \\
\hline & 2 & & & 56.07 & 1.00 & $32.5 \%$ \\
\hline & 3 & & & 57.71 & 1.03 & $32.6 \%$ \\
\hline Reference set & $\left({ }^{*}\right)$ & 20 & 31 & 31.49 & 1.02 & $21.8 \%$ \\
\hline
\end{tabular}

As we can see, the simulation results confirmed that the expected error was about $33 \%$ when 10 samples were used. By increasing the number of measurements to 20 (a common procedure), this error was decreased by $10 \%$. The most unbiased method was number 2 , used in the previous calculations for Ex1 and Ex2 (Figures 6 and 7).

Let us consider the worst-case scenario for Experiment 1 . If the $m_{1}=68$ is overestimated by $33 \%$, we will obtain a minimum value of the Weibull modulus close to 46 . This value is still significantly higher than was observed for the reference samples, equal to 31 - which is treated as given with sufficient certainty due to the higher number of data taken for calculations. $\mathrm{m}$ is often between 10 and 30 for gravity-filled castings [32], and the value $\mathrm{m}_{0}=31$ obtained without ultrasonication appears to be reliable and is not expected to be much higher.

Experiment 2 also showed improvement of the metal quality, which supports the hypothesis regarding the significant improvement in Ex1. In that case, if the error is maximal, the value will go down to about 40 , which still can be seen as an improvement in the metal quality.

The mechanical properties, according to the Hall-Patch equation, are expected to improve as the grain size decreases. Using the prediction from Figures 2 and 3, we can expect a better improvement of the metal quality in Ex1 than in Ex2. Those changes are reflected in the calculated Weibull modulus values-the highest value of 68 for Ex1 (with small scatter of data, the small error in Table 2) and a smaller value of 56 for Ex2. The gradual changes of $m$ according to the grain size can be treated as another validation of the established $\mathrm{m}$. Thus, the expected error is below the maximum possible value.

The Weibull modulus of UTS for good quality aerospace castings is expected to be between $50-100$ [32]. The $\mathrm{m}$ values characterising the processed alloys presented here fulfil those conditions.

\subsection{Role of Degassing and Structure Changes in Metal Straightening}

Two measurable changes can be discerned due to the sonication of the melt. The first one concerns the gas content, and the second concerns the grain size, reflecting changes on interfaces (forced wetting, undercooling, dispersion etc.). To find an answer as to which effect is dominant in the quality improvement obtained by the ultrasound, we need to recall the results of Ex5 (Tables 2 and 3).

The dataset for Ex 5 was produced following treatment by the contactless sonotrode in the setup, where the number of collapsing bubbles was not sufficient to cause grain refinement. In other words, most of the bubbles created oscillated in size but did not burst. Due to the lack of shock wave emissions, the expected de-agglomeration and particle dispersion could not happen, and thus we did not observe grain size reduction. Instead, processing by the contactless sonotrode caused degassing at the level of $0.06 \mathrm{~cm}^{3} / 100 \mathrm{~g}$, without noticeable grain size change; this effect on its own did not improve the metal 
strength or elongation. Similar processing, with the same level of the gas removed during treatment followed by grain refinement, improved the metal properties significantly.

Thus, the main mechanism involved in the metal strengthening observed in Ex1 and Ex2 was caused by a grain size decrease rather than decreased gas content. As a conclusion, it is necessary to achieve full cavitation at near-resonant frequency to cause changes at the interface that cause effective de-agglomeration and dispersion.

\section{Conclusions}

1. Contactless sonication provided significant changes in the observed microstructure of the cast alloy and decreased the grain size by up to $48 \%$.

2. The treatment was followed by a gas content decrease of up to $0.11 \mathrm{~cm}^{3} / 100 \mathrm{~g}$.

3. Ultrasonicated melts after casting exhibit improved the ductile properties, and the percentage of elongation increased maximally 1.7 times (from $16 \%$ to $28 \%$ ).

4. The processed alloy showed a great improvement in strength. The mean UTS was increased by about $17 \%$. This was followed by changes in the calculated Weibull modulus from 31 to 68 . Even considering the maximum possible error, the quality of the metal after treatment was significantly improved.

Author Contributions: Main author and experimental work, A.D.; grant holder and PI for Birmingham University, W.D.G.; technical revision, A.C.; some tests, Z.N.; contactless sonotrode concept K.A.P. and V.B.; simulation of resonant conditions used for experiments, V.B., G.D. and C.E.H.T.; and overall project leader and Greenwich University grant holder, K.A.P. All members contributed to the editing and provided material for the paper. All authors have read and agreed to the published version of the manuscript.

Funding: The authors acknowledge financial support from the ExoMet Project (EC contract FP7NMP3-LA-2012-280421), and EPSRC grants EP/P034411/1, EP/R002037/1, EP/R000239/1.

Institutional Review Board Statement: Not applicable.

Informed Consent Statement: Not applicable.

Data Availability Statement: Data is contained within the article.

Acknowledgments: The authors are grateful for the Covid-19 extension provided by the Universities of Birmingham and Greenwich.

Conflicts of Interest: The authors declare no conflict of interest.

\section{References}

1. Bruna, M.; Galčík, M. Casting quality improvement by gating system optimization. Arch. Foundry Eng. 2021, 1, $132-136$.

2. Dojka, R.; Jezierski, J.; Tiedje, N.S. Geometric Form of Gating System Elements and Its Influence on the Initial Filling Phase. J. Mater. Eng. Perform. 2019, 28, 3922-3928. [CrossRef]

3. Uludağ, M.; Gurtaran, M.; Dispinar, D. The Effect of Bifilm and Sr Modification on the Mechanical Properties of AlSi12Fe Alloy. Arch. Foundry Eng. 2020, 3, 99-104.

4. Abramov, O.V. Crystallization of Metals in Ultrasonic Field; Science-Moscow: Moscow, Russia, 1972.

5. Eskin, G.I. Ultrasonic Treatment of Molten Aluminum; Metallurgiya-Moscow: Moscow, Russia, 1965.

6. Eskin, G.I.; Eskin, D.G. Ultrasonic Treatment of Light Alloy Melts, 2nd ed.; CRC Press: Boca Raton, FL, USA, $2014 ;$ pp. 75-98.

7. Eskin, D.G.; Tzanakis, I.; Wang, F.; Lebon, G.S.B.; Subroto, T.; Pericleous, K.A.; Mi, J. Fundamental studies of ultrasonic melt processing. Ultrason. Sonochem. 2019, 52, 455-467. [CrossRef] [PubMed]

8. Vives, C. Grain refinement in aluminum alloys by means of electromagnetic vibrations including cavitation phenomena. JOM-e 1998, 50, 1-9.

9. Bojarevics, V.; Djambazov, G.S.; Pericleous, K.A. Contactless Ultrasound Generation in a Crucible. Met. Mater. Trans. A 2015, 46, 2884-2892. [CrossRef]

10. Pericleous, K.A.; Bojarevics, V.; Djambazov, G.; Dybalska, A.; Griffiths, W.D.; Tonry, C.E.H. Contactless Ultrasonic Cavitation in Alloy Melts. Materials 2019, 12, 3610-3622. [CrossRef] [PubMed]

11. Tonry, C.E.H.; Djambazov, G.; Dybalska, A.; Griffiths, W.D.; Beckwith, C.; Bojarevics, V.; Pericleous, K.A. Acoustic resonance for contactless ultrasonic cavitation in alloy melts. Ultrason. Sonochem. 2020, 63, 104959-104971. [CrossRef]

12. Eskin, G.I. Cavitation mechanism of ultrasonic melt degassing. Ultrason. Sonochem. 1995, 2, S137-S141. [CrossRef] 
13. Eskin, D.G. Overview of ultrasonic degassing development. In Light Metals 2017; Ratvik, A., Ed.; Springer: Cham, Switzerland, 2017; pp. 1437-1443.

14. Campbell, J. (Ed.) Chapter 6-Gas porosity. In Castings, 2nd ed.; Butterworth-Heinemann: Oxford, UK, 2003 ; pp. 178-204.

15. Leighton, T.G.; Walton, A.J.; Pickworth, M.J.W. Primary bjerknes forces. Eur. J. Phys. 1990, 11, 47-50. [CrossRef]

16. Khavari, M.; Priyadarshi, A.; Hurrell, A.; Pericleous, K.A.; Eskin, D.G.; Tzanakis, I. Characterization of shock waves in power ultrasound. J. Fluid Mech. 2021, 915, 1-14. [CrossRef]

17. Priyadarshi, A.; Khavari, M.; Subroto, T.; Conte, M.; Prentice, P.; Pericleous, K.A.; Eskin, D.G.; Durodola, J.; Tzanakis, I. On the governing fragmentation mechanism of primary intermetallics by induced cavitation. Ultrason. Sonochem. 2021, 70, 105260-105276. [CrossRef]

18. Fan, Z.; Wang, Y.; Xia, M.; Arumuganathar, S. Enhanced heterogeneous nucleation in AZ91D alloy by intensive melt shearing. Acta Mater. 2009, 57, 4891-4901. [CrossRef]

19. Wang, F.; Eskin, D.G.; Connolley, T.; Wang, C.; Koe, B.; King, A.; Reinhard, C.; Mi, J. In-situ synchrotron X-ray radiography observation of primary $\mathrm{Al}_{2} \mathrm{Cu}$ intermetallic growth on fragments of aluminium oxide film. Mater. Lett. 2018, 213, 303-305. [CrossRef]

20. Li, H.T.; Wang, Y.; Xia, M.; Zuo, Y.; Fan, Z. Harnessing oxides in liquid metals and alloys. In Solidification Science and Technology; Fan, Z., Stone, I., Eds.; Brunel University Press: London, UK, 2011; pp. 93-110.

21. Lee, S.B.; Kim, Y.M. Direct observation of in-plane ordering in the liquid at a liquid $\mathrm{Al} / \alpha-\mathrm{Al}_{2} \mathrm{O}_{3}$ (1102) interface. Acta Mater. 2011, 59, 1383-1388. [CrossRef]

22. Wang, F.; Tzanakis, I.; Eskin, D.G.; Mi, J.; Connolley, T. In situ observation of ultrasonic cavitation-induced fragmentation of the primary crystals formed in Al alloys. Ultrason. Sonochem. 2017, 39, 66-76. [CrossRef] [PubMed]

23. Pericleous, K.A.; Bojarevics, V.; Djambazov, G.; Dybalska, A.; Griffiths, W.D.; Tonry, C.E.H. The contactless electromagnetic sonotrode. In Shape Casting 2019; Tiryakioğlu, M., Griffiths, W.D., Jolly, M., Eds.; Springer: Cham, Switzerland, 2019 ; pp. $239-252$.

24. Tonry, C.E.H.; Djambazov, G.; Dybalska, A.; Bojarevics, V.; Griffiths, W.D.; Pericleous, K.A. Resonance from contactless ultrasound in alloy melts. In Light Metals 2019; Springer: Cham, Switzerland, 2019; pp. 1551-1559.

25. Pericleous, K.A.; Bojarevics, V.; Djambazov, G.; Dybalska, A.; Griffiths, W.D.; Tonry, C.E.H. Alloy grain refinement by means of electromagnetic vibrations. In Proceedings of the Liquid Metal Processing \& Casting Conference, Birmingham, UK, 8-11 September 2019; pp. 507-516.

26. Pericleous, K.A.; Beckwith, W.D.; Bojarevics, V.; Djambazov, G.; Dybalska, A.; Griffiths, W.D.; Tonry, C.E.H. Progress in the development of a contactless ultrasonic processing route for alloy grain refinement. IOP Conf Ser. Mater. Sci. Eng. 2020, 861, 012070-012078. [CrossRef]

27. Smith, W.F.; Hashemi, J. Foundations of Materials Science and Engineering, 4th ed.; McGraw-Hill: New York, NY, USA, 2006; pp. 242-243.

28. Zok, F.W. On weakest link theory and Weibull statistics. J. Am. Ceram. Soc. 2017, 100, 1265-1268.

29. Green, N.R.; Campbell, J. Statistical distributions of fracture strengths of cast $\mathrm{Al}_{7} \mathrm{SiMg}$ alloy. Mater. Sci. Eng. A 1993, 173, 261-266. [CrossRef]

30. Byczynski, G.E.; Campbell, J. The effects of oxide film defects on the strength and reliability of 319 alloy castings. In Advances in Aluminum Casting Technology II; Tiryakioğlu, M., Campbell, J., Eds.; ASM: Clevland, OH, USA, 2002; pp. 65-75.

31. Mi, J.; Harding, R.A.; Campbell, J. Effects of the entrained surface film on the reliability of castings. Met. Mater. Trans. A 2004, 35, 2893-2902. [CrossRef]

32. Campbell, J. Structure, defects and properties of the finished casting. In Castings, 2nd ed.; Elsevier: London, UK, $2003 ;$ p. 303.

33. Ono, K. A Simple Estimation Method of Weibull Modulus and Verification with Strength Data. Appl. Sci. 2019, 9, 1575-1614. [CrossRef]

34. Leighton, T.G. Acoustic Bubble Detection: II. The detection of transient cavitation. Environ. Eng. 1995, 8, 16-25.

35. Manoylov, A.; Lebon, G.S.B.; Djambazov, G.; Pericleous, K.A. Coupling of acoustic cavitation with DEM-based particle solvers for modeling de-agglomeration of particle clusters in liquid metals. Met. Mater. Trans. A 2017, 48, 5616-5627. [CrossRef]

36. Murty, B.S.; Kori, S.A.; Chakraborty, M. Grain refinement of aluminium and its alloys by heterogeneous nucleation and alloying. Int. Mater. Rev. 2002, 47, 3-29. [CrossRef]

37. Tiryakioglu, M.; Hudak, D. Guidelines for Two-Parameter Weibull Analysis for Flaw-Containing Materials. Met. Mater. Trans. B 2011, 42, 1130-1135. [CrossRef]

38. Tiryakioglu, M.; Hudak, D. Unbiased estimates of the Weibull parameters by the linear regression method. J. Mater. Sci. 2008, 43, 1914-1919. [CrossRef]

39. Tiryakioglu, M.; Hudak, D. On estimating Weibull modulus by the linear regression method. J. Mater. Sci. 2007, 42, 10173-10179. [CrossRef]

40. Hudak, D.; Tiryakioğlu, M. On comparing the shape parameters of two Weibull distributions. Mater. Sci. Eng. A 2011, 528, 8028-8030. [CrossRef]

41. Askeland, D.R. The Science and Engineering of Materials, 7th ed.; Cengage Learning: Boston, MA, USA, 2016 ; pp. $208-209$.

42. Weibull, W. A Statistical Distribution Function of Wide Applicability. J. Appl. Mech. 1951, 18, 293-297. [CrossRef]

43. Li, T.; Griffiths, W.D.; Chen, J. Weibull Modulus Estimated by the Non-linear Least Squares Method: A Solution to Deviation Occurring in Traditional Weibull Estimation. Met. Mater. Trans. A 2017, 48, 5516-5528. [CrossRef] 
44. Datsiou, K.C.; Overend, M. Weibull parameter estimation and goodness-of-fit for glass strength data. Struct. Saf. $2018,73,29-41$. [CrossRef]

45. Faucher, B.; Tyson, W.R. On the determination of Weibull parameters. J. Mater. Sci. Lett. 1988, 7, 1199-1203. [CrossRef] 